\title{
PROMOTING MEANINGFUL ASSESSMENT IN AN OVERCROWDED ENGLISH FIRST ADDITIONAL LANGUAGE INTERMEDIATE PHASE CLASSROOM
}

Sekanse A. Ntsala

University of the Free State

\begin{abstract}
This article provides prospects on how English First Additional Language (FAL) teachers working in overcrowded intermediate phase classrooms can assess meaningfully. It is in response to numerous reports that highlight the poor performance in English First Additional Language by South African intermediate learners. Seeing that overcrowdedness has been singled out as one of the possible causes of this reality, this paper integrates overcrowdedness as an important variable. This work, informed by the complexity theory, was steeped in phenomenology as a research design, resulting in the use of the interpretive paradigm. Qualitative research methods were used where interviews and observations provided insight into good practice. Data were analysed mostly thematically, ultimately revealing the significance of assessment tools, the length and weight of assessments, selective approaches to assessments, informal assessments, observations and group assessment. These results illuminated the nonlinearity of the language classroom since other teachers can assess productively despite the number of learners in their classrooms. A notable issue about the insights is that it is rewarding to combine ingenuity and simplicity.
\end{abstract}

Keywords: FAL, performance, assessment, good practice, complexity, nonlinearity.

\section{INTRODUCTION AND BACKGROUND}

South Africa (SA), like other sub-Saharan countries, is faced with the dilemma of poor literacy. The reports presented by the Progress in International Reading Literacy Study (PIRLS) released in 2006 and 2011 highlight the gravity of the situation in South Africa in the intermediate phase at school (Zimmerman and Smit (2014:1). The Southern and Eastern African Consortium for Monitoring Educational Quality (SACMEQ) also released a report that confirms this reality (Van den Berg, 2011:30). The report by SACMEQ affirms the reality that the intermediate learners in most other Southern African countries perform better in literacy than South African learners.

The second dataset is based mainly on the Annual National Assessments (ANA) that were introduced by the Department of Basic Education (DBE) in 2009. Since the inception of the ANA, various reports proved that intermediate learners, especially in the township schools, are not performing at the desired levels (DBE, 2012:3, 26-36; Free State Department of Education (FSDoE), 2010:9; MacFarlane, 2011:2). The reports further highlight English First Additional Language (EFAL) as the problem subject. 
This prompted some scholars to refer to this phenomenon as a disaster (Bloch, 2009:58). My interpretation is that Bloch is referring to a failing education system where learners do not acquire the intended benefits of learning EFAL. According to the Curriculum and Assessment Policy Statements (CAPS), intermediate learners are exposed to a first additional language (FAL) mainly to develop communication competencies (DBE, 2011:8). It means that if they fail the subject, this aim is not achieved. These realities raised the need to understand the reasons and to provide suggestions to remedy the problem. A number of sources were reviewed and several possible reasons emerged, with a sizable number of them highlighting over-crowdedness as one of the causes.

These studies show that classrooms are overcrowded in most parts of South Africa. The situation is so grave that in some schools up to a hundred learners share one classroom (Jika, 2016; Mafisa, 2013; Mdletshe, 2013; Velaphi, 2013). This situation raises various problems. There is an argument that learners in overcrowded schools perform badly in subjects such as mathematics and languages (Opotow, 2006:140). There is also a belief that in such schools, the quality of teaching is affected negatively (Govender, 2013:8). Joubert and Prinsloo (2013:15) argue that overcrowdedness is a serious threat to school safety. Savage and Savage (2010:71) associate the following with overcrowded classrooms: tiredness, aggression, defiance, anxiety in certain learners, limited privacy, competition for attention and negative effects on performance. Siyoko (2010:256) postulates that overcrowded classrooms may hamper learner-centred pedagogy. Class size is also considered a factor in teacher burnout (Chang, 2009:199).

The discussions in the previous paragraph highlight many serious impediments. Seeing that overcrowdedness is a reality in most parts of SA, this paper investigates how the effects of this phenomenon can be mitigated. An analysis of the situation in SA highlights the reality that the building of new schools and classrooms is not happening at a favourable rate due to issues such as incompetent contractors, lack of harmony between the Department of Education (DOE) and Department of Public Works (DPW) in some of the provinces, limited human resources in the rural provinces, the difficult natural terrain in certain provinces, rationalisation and learner migration (Parliamentary Monitoring Group, 2018). This means for some of the areas in SA the problem of overcrowded classrooms will remain a reality for some time. The teachers in this situation may appreciate assistance in terms of best practices. In support of this assertion, some scholars argue for the need to focus on researching the pedagogic processes that will suit large and small classes (O'Sullivan, 2006:26-29; Otienoh, 2010:57). This paper is informed by that narrative but its scope is limited to the aspects related to assessment.

Assessment has become a major policy issue in many countries (Cumming, 2009:91). Some argue that assessment is not only the heartbeat of the curriculum but also supports the intended curriculum (Ewing, 2013:12). In a language classroom, the assessor identifies performance, records progress, interprets results and make appropriate decisions (Bachman \& Palmer, 2010:86). It is a combination that requires talent and effort on the part of the assessor (Kiomrs, Abdolmehdi \& Naser, 2011:156). The authors reveal the concept of assessment literacy, which can be understood as the ability to assess meaningfully, to draw data from the assessment and to use the data meaningfully.

There is also a belief that the increase in additional language learners has increased the emphasis on language assessment (Blue, Milton \& Saville, 2000:7). This holds for a country like South Africa where there is evidence of poor performance in additional languages. 
According to McKay (2006:27-28), children in foreign language classes should be able to do the following at least: understand their teacher, master content, enjoy meaningful interaction, use reading and writing for communication, use the correct language for various contexts, and be able to self-regulate. Assessment is key in ensuring that these competencies have been attained and why Richards (2013:6) equates assessment to output.

South African intermediate teachers are also expected to engage learners in formal and informal activities regularly (DBE, 2011:93). This document indicates that assessment provides teachers with feedback that should inform future pedagogy. The challenge is that in an overcrowded classroom, the language teacher may feel overwhelmed by the situation and end up avoiding certain assessment requirements. In previous years, the challenge was covering the entire assessment plan but recently the department of education has reduced the number of expected formal tasks in the intermediate phase to thirteen per annum, including the examination. This will surely ease some of the pressure on teachers.

The same amendment, however, still emphasises informal assessments that should ideally precede all the formal tasks. As a matter of principle, the informal assessments may have to be repeated, especially if there is evidence that the learners are struggling. The reality then is that intermediate phase teachers are still faced with an enormous task, especially those working in schools where EFAL is a challenge. Overcrowdedness, which is a reality in some schools, obfuscates the situation even further. At the same time, these EFAL teachers in overcrowded classrooms still have to assess and provide explicit feedback, as this enhances learning (Lantoff \& Poehner, 2010:17). This paper explicates how this can happen meaningfully.

\section{THEORETICAL FRAMEWORK}

The Complexity Theory (CT) guided the empirical processes in this study because the emphasis of CT is the study of complex systems. This theory raises a new agenda for the philosophy of education (Morrison, 2008:23). The latter statement expounds on the reality that this theory provides a new perspective in terms of how educational research should be conducted. Larsen-Freeman (2013:369) see it as a multi-focused theory since it can ground research on language development, language learning, language evolution, language use and language change. CT is characterised by attributes such as interaction, adaptation, interconnectedness, self-organisation, openness, dynamism, nonlinearism and emergence most of which resonates with the realities of a language classroom (Larsen-Freeman and Cameron, 2008:2-4).

Interaction means that various components relate and influence one another to a certain degree. In the case of language teaching in South Africa, examples such as the teacher, teacher competency, the learner, motivation, resources, socioeconomic issues and issues of support can be highlighted as components that interact in one way or the other. Nonlinearity refers to the disproportionate relation between cause and effect (Vetromille-Castro, 2013:628). An example of this can be two schools in the same vicinity, catering for the same community yet producing different results. Openness exposes the actuality that complex systems are affected by outside influences (Mercer, 2013:377). Indeed, the language classroom is open because certain outside decisions can influence classroom practice. The appointment of teachers as well as the district office are examples of this. The competency of the district officials can and will ultimately affect performance in the classroom in one way or 
the other. Self-organisation and emergence refer to the absorption of new behaviour and elements (Vetromille-Castro, 2013:627).

The above-mentioned are attributes expected from reflective teachers. This absorption of new behaviour will arguably lead to further emergence, making this a type of a cyclical process. Dynamic systems change over time whereas adaptation in a complex system is the process by which a system adjusts itself in response to changes in its environment (De Paiva Franco, 2013:647-647). Language teaching is also dynamic, especially in those instances where schools and teachers see the need to align themselves with the prescripts of the $4^{\text {th }}$ industrial revolution.

CT mostly informed the data collection as well as the data analysis phases of the study. The practices that had been discussed during data analysis were carefully compared to the characteristics explained above.

\section{DESIGN AND METHODOLOGY}

The study was interpretive by nature because the objective was to determine the ideas that the EFAL teachers in the intermediate phase possess about their world (Thomas, 2009:75). Phenomenology as a research design made it possible to put aside all judgements and collect data on how teachers make sense of their own experiences (McMillan \& Schumacher, 2006:26).

Participation was sought by purposive sampling which is a nonprobability sampling method. This method made it possible to identify cases that fit the set criteria and to select especially informative cases (Neuman, 2007:141). All the participants are teaching EFAL in overcrowded intermediate schools and all of them have been teaching for five years or more.

The participants were selected from both the best performing and the struggling schools in the Motheo education district in the Free State province. This district drafts a list of best performing and struggling schools which is informed by performance in English and mathematics. The following ethical processes were implemented before the commencement of the empirical processes: receiving ethical clearance from the University, receiving permission from the Free State Department of Education and the principals of the selected schools, and ensuring that the participants sign consent forms that guarantee their anonymity.

In the first phase of data collection, eight teachers from poorly performing schools were interviewed in a group. The objective was to get to the bottom of the problems faced by the teachers. In the second phase of data collection, eight teachers from the best performing schools were interviewed individually to identify good practices. The latter objective informed the observation of three other teachers in practice, who are also working in the schools listed as best performing.

Based on the advice of Johnson and Christensen (2012:34), data analysis was descriptive, with the focus on finding patterns, themes and holistic features. The only difference is that with observations, the analysis focused on the notes made in the observation schedules. The interpretation of the data followed the following sequence: transcription, segmenting and coding, and the establishment of categories and themes. Some of the themes that emerged during the group interview shaped the questions for the individual interviews. 
The methodology presented a few limitations. The main challenge was with the group session because the participants were initially economical with information. This required that the researcher invested some time in setting them at ease. It was reaffirmed that the information they contribute will ultimately result in recommendations that may benefit the profession. They were also reminded of the consent forms that guaranteed their anonymity. This resulted in them volunteering more information, especially on the issue of the challenges encountered.

\section{FINDINGS AND DISCUSSIONS}

The data produced many discussions and themes. For the sake of this paper, only the discussions relevant to assessment are addressed, because the challenges highlighted by the teachers in terms of their practice are more inclined towards assessment.

\section{Assessment Tools Used in Overcrowded EFAL Classrooms}

The complexity of the language classroom means that a teacher has to possess many skills, each comprising many activities that have to be assessed differently, using different tools. The data show that teachers use a rubric to assess almost all the language skills except language structures and conventions. Interviewees stated the following:

P3 'Like I said before we have done two oral tasks. They come individually in front of the class. I use rubrics to allocate marks. I discuss the rubrics with them at the beginning of the year. They are familiar with the contents of the rubrics ...'

P1 'When we assess essays, we have rubrics that tell us how/what to assess. They write writing, punctuation, language. We explain to them the contents of the rubrics early in the year to make sure they know what is required'.

A rubric seems to be a popular assessment tool. The observations highlighted that a rubric is also used to assess all other skills except grammar. The use of rubrics by teachers is a good practice as this can lead to the attainment of quality assessment (McMillan, 2014:231). Using rubrics can raise awareness among learners of particular problems in an attempt to minimise their re-occurrence. Furthermore, the use of rubrics ensures consistency in marking, which results in fairness. Additionally, having to indicate the appropriate level descriptors in a rubric seems to be more convenient and time-saving than writing out comments in each learner's book. The group participants, unfortunately, did not mention the use of a rubric. Nevertheless, the objective is not to apportion blame since those participants are working in a complex environment. The concern though is that the intermediate phase EFAL teachers working in overcrowded classrooms and who are not using a rubric as an assessment tool may be missing out on its pedagogical benefits.

In terms of the language structures and conventions, a memorandum was the only tool mentioned by the interviewees as an assessment tool. It has to be noted that in most instances, the language structures and conventions were integrated and assessed together with the other skills. In those situations, the criteria in the rubric cover the grammar aspect. This leads to the reinforcement of grammatical knowledge in context which is meant to ultimately limit mistakes and save time in the consequent assessments. Apart from the assessment tools discussed in this section, the participants demonstrated that they respect inclusive practices as will be discussed next. 


\section{Inclusive Strategies}

Teachers should be inclusive in their practices (Donald, Lazarus, \& Lolwana, 2010:16); this has to be evident even in their assessment practices. It means a teacher should cater for the needs of all learners - a goal that may seem impossible in an overcrowded classroom. Nevertheless, the following practices symbolise the reality that some intermediate EFAL teachers do make an effort to pay attention to all the learners.

P8 'With speaking, I try not to waste time on the good speakers. I give them a short chance so that they do not feel sidelined. They get enough time when we do informal. I use them to motivate the others ...'

P2 '... The thing is because of time I will focus more on the struggling ones. It takes me a long time because for one hour I only do half a class. The good ones I do not spend a lot of time on them. I try to cover all the reading methods though, even though it is difficult.'

What is evident is that some teachers try to individualise in their language classrooms. This means those learners with problems will receive more attention. This may seem timeconsuming in the initial stages but it will benefit the teacher in the follow-up assessment practices as the gaps in competency would have been addressed. The teachers following this approach are adaptive and dynamic but they should take care to avoid neglecting the other learners altogether. Teachers who have this mind set are life performers, they are innovative, ingenious, risk-takers and independent thinkers (Jansen, 2011:5). Although this may be a good practice, it is important to mention that gifted learners should not feel underused or undervalued in class. They must be kept busy with meaningful activities and at a certain point, should also enjoy undivided attention from their teachers.

\section{Formal Versus Informal Assessment}

Assessment in all its forms is important in the EFAL classroom because it is expected to enhance performance (DoBE, 2011:93-94). This departmental guideline further states that both formal and informal assessments should take place. As indicated in the earlier discussions, this is one requirement that may be neglected because of the high number of learners per class. Informal assessments in particular, may be neglected. This was revealed by the group interviewees who pointed out that they do not have time to cover all the items in the teaching plan as well as assess everything both formally and informally. This is detrimental in many ways because informal assessments assist teachers in determining the level of understanding and allow the teacher to do necessary adjustments in terms of strategies (McMillan, 2014:97). Fortunately, some of the teachers still go out of their way to assess informally as the statement below highlights.

P4 '... the next day they do it as an informal classwork. After that, I take the books and correct them. Yes, it works for me ... You know what I did in my class, let us say for instance we are reading a reader. I read for them. I ask them to point when I am reading. I move around to capture their attention. It helps me to see whether the learner can see where I am reading. After reading for them I read together with them. Every sentence I read twice.' 
This illustrates not only that informal assessment takes place but also how it is done. The observed teachers also employed informal assessment during listening and speaking, writing and presenting, and grammar. This practice supports the view of Goldenberg (2008:14) who advocates for a recursive process of teaching, assessing, reviewing, making adjustments and reteaching. The assertion is that focus on informal assessment will eventually reduce workload during formal assessment because the learners have an idea of what is required of them. When this happens, the teacher begins to assess faster and with less stress. This practice also supports the prescripts of fair assessment and may lead to improved performance. The next discussion expounds on the importance of peer assessment.

\section{Peer Assessment in an Overcrowded Intermediate Phase EFAL Classroom}

It subsequently came to light that the interviewees from the best performing schools use peer assessment extensively. This is another practice that the group participants (those in poor performing schools) did not mention. The presumption is that those who employ this strategy ultimately benefit as peer assessment paves the way for a successful and quicker formal assessment. The benefit in terms of saving time cannot be overemphasised: because the learners shoulder some of the burden, the teacher's workload is lighter. Learners share the responsibility in terms of explaining the shortcomings to their peers and 'scaffold' them where possible, thereby facilitating better understanding. Furthermore, this approach seems to be learner-centered by nature with the possibility of improving performance in EFAL classrooms.

\section{Constructive Practices}

This section highlights the practices that are in line with the prescripts of a constructive classroom. These are the practices that promote active participation in pursuance of effective learning (Killen, 2015:45). Assessing learners in a group is one of such practices, as the statements below shows.

P3 'Speaking also. They can prepare in groups. The entire group will stand in front and one of them will present. The others will answer questions.'

P4 'Group work helps because it saves time, but I always make sure that each learner gets what he/she deserves. Each learner's book will be controlled. I do not give marks to names. I attach credits to the books. I focus more on the first one or two books though. The others I just attach a mark and a signature.'

P $8 \quad$ '... When they read I can say they should read as a group of six and while they are reading I will identify who is reading fluently because I stand close to them, then I give them marks. I also note who could not read in that group. I go to another group. When I am done, it is only then that I give the struggling ones a chance to read individually, and I will be helping them ...'

In the above quotations, it is clear that it is possible to implement group work when assessing listening and speaking, writing and presenting, as well as reading and viewing. Again, the benefits for an overcrowded classroom are indisputable. Group work may reduce the time taken for assessing a task since a similar mark is allocated to the whole group in most cases. This, however, does not mean learners working in a group cannot be allocated different marks and this should be discussed in advance in order to promote maximum participation. 
Assessing both listening and speaking as well as reading and viewing in a group seems to be a dynamic and adaptive practice on the part of those teachers concerned. This is because only written activities are assessed in a group in most primary schools. It also shows that some teachers can self-regulate.

EFAL teachers should not forget that group work can also have some drawbacks. Taqi \& AlNouh (2014:56) highlight issues such as unequal effort, some learners dominating the group, promotion of parasitic practices, poor communication, learner's side lining each other, the difficulty of grading each group member, time taken for the task, reluctance to take orders from peers, commotion and noise, lack of feedback, and different language preferences. A look at this list affirms the belief that if the teacher is not hands-on, a group activity can turn into a disaster. Group activities have to be planned and managed effectively to be successful at all.

There is also evidence that effective construction of knowledge takes place during the assessment of grammar. The statement below indicates that during grammar exercises, some intermediate phase EFAL teachers encourage the learners to think of and write their own sentences.

P8 ' ... when we do grammar I always make sure that they use the language items in their own sentences. That is very important because then they do not forget.'

The same practice was noticed during the observations: when learners write their own sentences they stand a better chance of internalising the language item and to understand its use better. This translates into constructive assessment which is encouraged by some scholars (Waugh, Warner \& Waugh, 2016:18). The process, however, should start with teachers providing the learners with ample examples. The teachers using this approach have decided to stick to the basics despite their classrooms being overcrowded. The benefits of this practice in an overcrowded classroom may not be obvious but the belief is that a deep understanding of the language items will be beneficial in subsequent assessments, as the learners get most of the answers correct. Once this happens, teachers manage to assess and progress through the programme faster and with less strain.

\section{Observations During Assessments}

The discussions in this section focus on the 'during assessment' processes. The collected data illustrated the reality that some of the participants actively observe the proceedings during various activities as the following statement highlights.

P1 '... Yes I prefer that one because you can be able to walk in between them when they $($ sic $)$ still writing because when they are sitting there you think that they are writing only to find out that they are sitting doing nothing. So I use the column one so that I can go around checking whether they are doing their work. Whether they are writing the correct thing and when see a wrong thing I will tell the learner this is wrong. Read the question again and do the correct thing.'

Observations in the context of this discussion do not refer to an assessment type or a data collection method but are discussed as a classroom activity on the part of the teacher. This is a meaningful practice because observations, as part of an assessment activity, allow the teacher to determine the following: student participation, interpersonal skills, correctness of 
responses, verbal skills, the need for more examples, the identity of at-risk learners, the interest level and the level of understanding (McMillan, 2014:97). The practice enables immediate feedback and is beneficial because noticing and addressing problems on time may save the teacher some time when marking due to fewer mistakes by the learners. It may even reduce or eliminate the need for extra classes.

\section{Short Assessments}

The data also highlighted the importance of short assessments. This became evident during the observations when the teachers assessed writing and presenting. The learners were required to write short, informal essays. It also happened during grammar lessons where the learners were instructed to write short class works of not more than five sentences. This strategy may well suit those working in overcrowded classrooms since it eliminates the temptation to avoid assessment. The teacher can assess quickly and also provide feedback. If executed well, the learners will benefit in terms of getting enough practice. The teacher is able to assess all the learners regularly, a critical requirement in the Education White Paper 6 and CAPS (Du Plessis, Conley \& Du Plessis, 2007:45; DoBE, 2011:93).

\section{Note-Taking}

One critical observation was that some teachers allowed learners to take notes during listening and speaking sessions. The learners had mastered the practice of listening and taking down notes at the same time. It has to be highlighted though that those teachers accommodated the learners in terms of pace and did not rush them. This occurred even during formal assessments. This is not a popular practice, but everybody, including the teachers, benefitted. The learners were not reluctant step forward to present or discuss because they had notes to refer to when they encountered problems. This resulted in quicker proceedings and higher involvement levels. This strategy can very easily be extended to other oral activities, where learners can be allowed to note down key facts on flashcards and refer accordingly.

These may be critical accommodations for an EFAL classroom, especially for struggling learners, yet they do not negate the fact that ultimately, learners should be able to rely entirely on memory. As Lantolf and Poehner (2010:14) postulate, teachers should be dynamic enough in their attempts to promote an understanding of the world. This is one of those dynamic strategies that can benefit both teachers and learners in overcrowded intermediate phase classrooms.

\section{CONCLUSION}

This paper explicated the assessment practices that EFAL teachers working in overcrowded intermediate phase classrooms should consider using. The discussions in this paper elaborated on the dynamism and the adaptability of the teachers concerned, particularly those from well-performing schools. It also explains the nonlinearity of the intermediate phase EFAL classroom, seeing that the teachers from the poorly performing schools could not mention most of these practices, despite all the sampled schools serving the same type of learner and community. There may be tangible reasons why these teachers have not mentioned some of the practices that are professed to be good. These reasons may be teacherspecific, or they may be a result of contextual factors. Nonetheless, this paper has highlighted that meaningful assessment in overcrowded classrooms need not be exclusive. Teachers 
mostly just need to be resourceful. Sometimes the desired level of inventiveness pivots on an element of motivation and willpower on the part of the teacher.

\section{REFERENCES}

BACHMAN, L \& A PALMER. 2010. Language assessment in practice. Oxford: New York.

BLOCH, G. 2009. The toxic mix: What's wrong with South Africa's schools and how to fix it? Cape Town: Tafelberg.

BLUE, GM, J MILTON \& J SAVILLA. 2000. Assessing English for academic purposes. New York: Peter Lang.

CHANG, M. 2009. An appraisal perspective of teacher burnout: Examining the emotional work of teachers. Educational Psychology Review, 21(1): 193-218.

CUMMINS, A. 2009. Language Assessment in education: Tests, curricula, and teaching. Annual Review of Applied Linguistics, 29(1): 90-100.

DE PAIVA FRANCO, C. 2013. Understanding digital natives' learning experiences. RBLA, Belo Horizonte, 13(3): 643-658.

DONALD, D, S LAZARUS, \& P LOLWANA. 2010. Educational Psychology in social context: Ecosystemic application in Southern Africa, $4^{\text {th }}$ ed. Cape Town: Oxford.

DU PLESSIS, P, L CONLEY \& E DU PLESSIS. 2007. Teaching and Learning in South African Schools. Pretoria: Van Schaik.

EWING, R. 2013. Curriculum and Assessment, $2^{\text {nd }}$ ed. Melbourne: Oxford.

GOLDENBERG, C. 2008. Teaching English language learners: What the research does - and does not - say. Open Educational Resources, 32(2): 7-44.

GOVENDER, P. 2013. Hop, skip and jump to a better education. Sunday Times, 8 September: 5.

JIKA, T. 2016. Where kids go to school in a mud cowshed: Smaller schools left behind in upgrade initiative. Sunday Times 20 May: 6.

JANSEN, J. 2011. Great South African teachers: A tribute to South Africa's great teachers from the people whose lives they have changed. Johannesburg: McMillan.

JOHNSON, B \& L CHRISTENSEN. 2012. Educational research: Quantitative, qualitative, and mixed approaches, $4^{\text {th }} \mathrm{ed}$. Los Angeles: Sage.

JOUBERT, R. \& S PRINSLOO. 2013. Creating safe and effective classrooms. Pretoria: Van Schaik.

KILLEN, R. 2015. Teaching strategies for quality teaching and learning, $2^{\text {nd }}$ ed. Cape Town: Juta \& Company.

KIORMS, R, R ABDOLMEHDI \& R NASER. 2011. On the interaction of test washback and teacher assessment literacy: The case of Iranian EFL secondary school teachers. English Language Teaching, 4(1): 156-161.

LANTHOF, JP, \& ME POEHNER. 2010. Dynamic assessment in the classroom: Vygotskian praxis for second language development. Language Teaching Research, 15 (1): 11- 33. LARSENFREEMAN, D. 2013. Complexity Theory: A New Way to Think. R.B.L.A, Belo Horizonte, 13(2): 369-373.

LARSEN-FREEMAN, D \& L CAMERON. 2008. Complex systems and applied linguistics. Oxford: Oxford University Press.

MAFISA, I. 2013. Parents scramble to register kids. New Age, 9 January 2013: 7.

MACFARLANE, D. 2011. The damage schools do to children. The Teacher, July 2011: 2.

MCKAY, P. 2006. Assessing young language learners. Cambridge: Cambridge University Press.

MCMILLAN, JH. 2014. Classroom assessment: Principles and practice for effective standards-based instruction, $6^{\text {th }}$ ed. Boston: Pearson.

MCMILLAN, JH \& S SCHUMACHER. 2006. Research in Education: Evidence-based inquiry, $6^{\text {th }}$ ed. Boston. Pearson.

MDLETSHE, C. 2013. School handicapped: Shortage of classrooms hinders disabled pupils. Sowetan, 5 February 2011: 8.

MERCER, S. 2013. Towards a complexity-informed pedagogy for language learning. RBLA, Belo Horizonte, 13(2): 375-398. 
MORRISON, K. 2008. Complexity theory and the theory of education. Educational Philosophy and Research, 40(1): 4-18.

NEUMAN, WL. 2007. Basics of social research: Qualitative and quantitative approaches, $2^{\text {nd }}$ ed. Boston: Pearson.

O'SULLIVAN, MC. 2006. Teaching large classes: The international evidence and a discussion of some good practice in Ugandan primary school. International Journal of Educational Development, 26: 24-37.

OPOTOW, S. 2006. Rationalities and levels of analysis in complex social issues: The examples of overcrowding and poverty. Social Justice Research, 19(1): 135-150.

OTIENOH RO. 2010. The issue of large classes in Kenya: The need for professional support for primary school teachers in school contexts. ISEA, 38(2): 57-72.

PARLIAMENTARY MONITORING GROUP, 2018. School infrastructure: Update on ASIDI, with Deputy Minister. Available from https://pmg.org.za/committee-meeting/25904/ [Accessed: 27/01/2020].

RICHARDS, JC. 2013. Curriculum Approaches in Language Teaching: Forward, central, and backward design. RELC Journal, 44(1): 5 - 33 .

SAVAGE, TM \& MK SAVAGE. 2010. Successful classroom management and discipline: Teaching self-control and responsibility, $3^{\text {rd }} \mathrm{ed}$. Los Angeles: Sage.

SIYOKO, L. 2010. Central challenges of implementing learner-centred pedagogy: The case of the problem-solving approach in Uganda. Cambridge Journal of Education, 40(3): 247-263.

SOUTH AFRICA. FREE STATE DEPARTMENT OF EDUCATION. 2010. Quality learning and teaching campaign. Report. South Africa.

SOUTH AFRICAL. DEPARTMENT OF BASIC EDUCATION. 2011. Curriculum and Assessment Policy Statement: English First Additional Language. Intermediate Phase Grades 4-6. Pretoria: Government Printer.

SOUTH AFRICAL. DEPARTMENT OF BASIC EDUCATION. 2012. Report on the annual national assessments. Pretoria: Government Printer.

SOUTH AFRICAL. DEPARTMENT OF BASIC EDUCATION. nd. Curriculum and Assessment Policy Statement: Intermediate Phase Grades 4-6. Pretoria: Government Printer. Available from https://skole.co.za/wp-content/uploads/2019/11/Intermediate-Phase-CAPSAmendments.pdf [Accessed: 12/12/2020].

TAQI, HA. 2014. Effect of group work on EFL students' attitudes and learning in higher education. Journal of Education and Learning, 3(2): 52-65.

THOMAS, G. 2009. How to do your research project: A guide for students in education and applied social sciences. Los Angles: Sage.

VAN DEN BERG, S. 2011. We are failing our kids. City Press 25 September: 30.

VETROMILLE-CASTRO, R. 2013. Social interactive entropy and interaction in the language teacher education classroom. RBLA, Belo Horizonte, 13(2): 625-641.

VELAPHI, S. 2013. Parents to march for teachers: Parents fed up with overcrowded classes. The New Age 5 March: 25.

WAUGH, D, C WARNER \& R WAUGH. 2016. Teaching grammar, punctuation, and spelling in primary schools. London: Sage.

ZIMMERMAN, L \& B SMIT. 2014. Profiling classroom reading comprehension development practices from the PIRLS 2006 in South Africa. South African Journal of Education, 34(3): 1-9.

\section{BIOGRAPHICAL NOTE}

Dr Sekanse Abiner Ntsala is a former English teacher. He is now a lecturer in the School of Social Sciences and Language Education in the Faculty of Education at the University of the Free State. He is mainly responsible for English Language education, and he is presently the discipline co-ordinator for Language Education in the faculty. His main research interests include Language Education, Language Endangerment and Community-Based Research. 